\title{
STOCHASTIC MEASUREMENT OF NOISE TRUE RMS USING TWO-BIT FLASH A/D CONVERTERS
}

\author{
Platon Sovilj, Bojan Vujičić, Matija Sokola, Dragan Pejić, Željko Beljić, Zoran Mitrović
}

Original scientific paper

The paper presents an application of the stochastic measurement approach for true RMS and power of noise. The instrument structure is based on two 2bit flash analog-to-digital (A/D) converters whose inputs are the dithered noise, and on accumulation of the product of the converters' outputs. New theoretical expressions for predicting measurement result and measurement uncertainty, with inclusion of input signal's stochastic nature, are derived. Extensive simulations and experiments prove the validity of the proposed method and its low measurement uncertainty, even at a relatively low sampling rate. These indicate that, beside general applications for noise measurements, the instrument is suitable for chemical and biological substances detection that utilizes graphene sensors.

Keywords: digital measurements; measurement uncertainty; noise measurement; stochastic processes

\section{Stohastičko mjerenje efektivne vrijednosti šuma dvo-bitnim flash A/D konvertorima}

Izvorni znanstveni članak U ovom radu je predstavljena primjena pristupa stohastičkog mjerenja u mjerenju efektivne vrijednosti i snage šuma. Struktura instrumenta je zasnovana na dva dvo-bitna flash analogno-digitalna (A/D) konvertora, na čije ulaze se dovodi diterovani šum, i na akumulaciji proizvoda konvertorskih izlaza. Izvedeni su novi teorijski izrazi za predviđanje rezultata mjerenja i mjerne nesigurnosti, koji uključuju stohastičku prirodu ulaznih signala. Ekstenzivne simulacije i eksperimenti dokazuju validnost predložene metode i njenu nisku mjernu nesigurnost, čak i pri relativno niskoj frekvenciji uzorkovanja. Ovo ukazuje da je prikazani instrument, osim za opću primjenu u mjerenju šuma, pogodan i za detekciju kemijskih i bioloških tvari, zasnovanu na upotrebi grafenskih senzora.

Ključne riječi: digitalna mjerenja; mjerenje šuma; mjerna nesigurnost; stohastički procesi

\section{Introduction}

Commonly used strategy in discrete digital measurements [1, 2], called "measurement in a point", is to capture a precise digital value of signal's magnitude at a chosen time instant. The measurement uncertainty is estimated using the applied theory of discrete signals and systems, underpinned by algebraic calculations [3]. An alternative strategy, the "stochastic measurement over an interval" [4], has been researched in three challenging areas: measurements that require high accuracy and linearity [5-7], measurement of fast-changing signals and noisy signals $[8,9]$. Numerous simulations, prototype instruments and experiments have proven the metrological applicability of the stochastic approach [4-9].

Noise is a highly unwanted factor in precise calibration procedures, telecommunications, biomedical measurements, space research etc. [10-14]. This is especially true for measurement and control systems based on the null detection.

On the other hand, there are applications that require detection and precise measurement of noise-like scattered signals. One of them is the latest technology of graphenebased chemical and biological sensors [15-18], where the interaction between the substance molecules and the graphene sensor surface molecules creates a lowfrequency noise. Physical principles of unique identification of chemical or biological substance by a graphene sensor are described in [15]. Precise measurement of power spectral density of this lowfrequency noise, has the key role in substance identification. For a known geometry of graphene sensor's active surface, the substance concentration is proportional to the noise power.
Design and realization of precise, accurate, reliable and autonomous (battery-operated) graphene sensor of chemical and biological substances bring the array of practical engineering challenges. These have been mostly resolved to a satisfactory level, but the low power consumption is still a serious obstacle.

In standard approach (based on measurement in a point), the noise power is usually obtained as the integral (by frequency) of the noise power spectral density over a selected frequency range. Hence it is necessary to calculate precise values of power density at a number of frequencies, usually by FFT algorithms applied on an array of digitized samples. This approach is demanding in terms of computing, time and energy, also requiring a complex instrumentation. The exact frequencies with the pronounced power densities can be later used for identification of the substance type.

However, if the concentration of chemical and biological substances is very low, the precise identification is not needed. It is only necessary if the concentration is above a selected threshold value.

This opens a possibility of splitting the problem into two phases. The first phase simply answers the question "is there any substance?", and only if the answer is positive, a more detailed measurement process is initiated, in order to identify "what is it?" and "what is its concentration level?".

The "measurement over an interval" approach is very suitable for direct measurement of power i.e. the true RMS value of signals [4-7]. Hence it is capable of answering the first question with much simpler hardware and lower energy consumption with respect to the standard approach solutions. A similar instrument, also based on low-bit flash A/D converters [18], can be activated for the second phase, in order to measure power 
densities at specific frequencies. The process of initial concentration detection of the first phase is now independent from measurement and identification process of the second phase.

This paper deals with a measurement structure with two 2-bit flash A/D converters, a 2-bit multiplier (with only 6 two-inputs gates) and two counters. Such structure was used to measure the power or RMS of deterministic signals [4-7], but here it is utilized to measure the total (integral) noise power in the initial (first) phase. It enables a straightforward determination whether it is necessary to start the complex measurement processes of the identification (second) phase.

The aim of this paper is to show the viability of the "stochastic measurement over an interval" approach for precise measurement of total noise average power over a time interval. The model of a stochastic instrument $[4,5$, 7] is employed, but a novel analysis of measurement result and measurement uncertainty is proposed. The theoretical considerations for the first time incorporate the detailed analysis of the influence of input signal's stochastic nature onto the measurement process. Theoretical predictions are verified by numerous simulations for the two most important cases in practice Gaussian and uniform noise. Experiments, conducted for uniform noise, show a very good match with the theory, with the simulations and with the standard instrument FLUKE 8846A.

Regarding graphene-based sensors, these results confirm that the problem of initial detection ("is there any substance?") can be solved by the proposed instrument.

\section{Theory of operation}

\subsection{Model of the proposed stochastic instrument}

The structure of the two-bit flash A/D converters instrument for measurement of noise power, based on stochastic measurement over an interval approach, is presented in Fig. 1. The instrument has no sample and hold circuits at the input but includes operational amplifiers which work as high-speed comparators, whose outputs can be $-10 \mathrm{~V}$ or $+10 \mathrm{~V}$. These voltage levels are limited to $0 \mathrm{~V}$ and $5 \mathrm{~V}$ by level limiter (LL) circuits, shown in Fig. 2. Thus, each A/D converter consists of two comparators and two LL circuits, as shown in Fig. 1 by a dashed box.

Inherently large quantization error of 2-bit $\mathrm{A} / \mathrm{D}$ conversion is practically eliminated by analogue superposition of two random uncorrelated dither signals $h_{1}$ and $h_{2}$ onto the input noise signal $s$, as well as by averaging the product $\Psi=\Psi_{1} \cdot \Psi_{2}$ [4]. Variables $\Psi_{1}$ and $\Psi_{2}$ are digitized samples expressed as:

$\Psi_{i}=\left(b_{1 i}-b_{-1 i}\right) \cdot 2 g$

where $g$ is the threshold, A/D outputs $b_{1 i}, b_{-1 i} \in\{0,1\}$ and $i=1$, 2. The upper counter in Fig. 1 performs the accumulation (i.e. integration) of $\Psi$ over the measurement interval, whereas the lower one counts the number of samples $N$. At the end of each measurement interval, both accumulated values are passed to a PC for averaging and scaling. The counters are then reset, enabling the measurement to be repeated over and over again. For proper operation, the noise signal $s$ should be within the instrument range $\pm 2 g$ and the dither signals $h_{1}$ and $h_{2}$ should be appropriately scaled with respect to the threshold $g$, i.e. the following conditions must be satisfied [4-9]:

$|s| \leq 2 g,\left|h_{i}\right| \leq g,\left|s+h_{i}\right| \leq 3 g ;(i=1,2)$

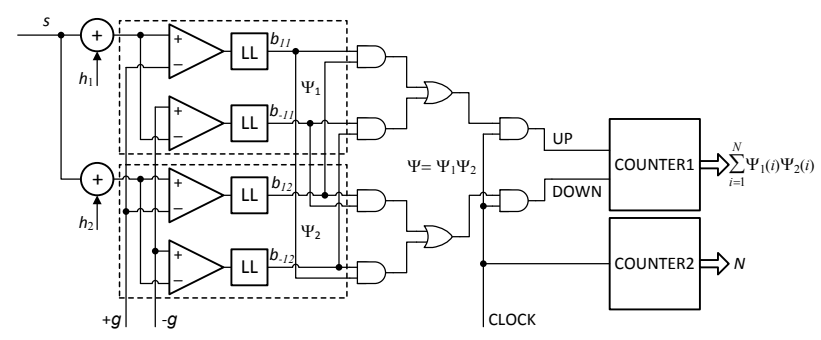

Figure 1 Model of the proposed stochastic instrument with 2-bit flash $\mathrm{A} / \mathrm{D}$ converters

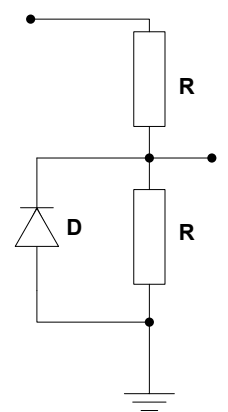

Figure 2 Electrical circuit of Level Limiter (LL)

\subsection{Instrument output for infinite number of samples}

Due to a great speed of implemented electronic components and the consequent huge number of samples within the measurement time interval, both the statistic theory of samples and the Central limit theorem are utilized. Similarly to instruments for measuring true RMS value [5-7], the average noise power is obtained as:

$\overline{s^{2}} \approx \bar{\Psi}=\frac{1}{N} \sum_{i=1}^{N} \Psi_{1}(i) \cdot \Psi_{2}(i)$,

where $\bar{\Psi}$ is the average of the product $\Psi=\Psi_{1} \cdot \Psi_{2}$. Let us investigate $\bar{\Psi}$ in the ideal case of infinitely high number of samples. Now $\Psi$ is considered as a stochastic variable:

$\bar{\Psi}=\int_{-\infty}^{+\infty} \Psi \cdot \mathrm{d} P_{\Psi}$,

where $\mathrm{d} P_{\Psi}$ is the infinitesimal probability for product $\Psi$ to assume a certain value, which can be represented as the product of infinitesimal probabilities of its factors:

$\mathrm{d} P_{\Psi}=\mathrm{d} P_{h_{1}} \mathrm{~d} P_{h_{2}} \mathrm{~d} P_{S}$

The factors from Eq. (5) are: 


$$
\mathrm{d} P_{h_{1}}=\frac{1}{2 g} \mathrm{~d} h_{1}, \mathrm{~d} P_{h_{2}}=\frac{1}{2 g} \mathrm{~d} h_{2}, \mathrm{~d} P_{s}=p(s) \mathrm{d} s
$$

Because $h_{1}, h_{2}$ and $s$ are mutually uncorrelated, substituting Eq. (5) and Eq. (6) into Eq. (4) yields:

$\bar{\Psi}=\int_{-\infty}^{+\infty} p(s) \mathrm{d} s \int_{-g}^{g} \frac{\Psi_{1}}{2 g} \mathrm{~d} h_{1} \int_{-g}^{g} \frac{\Psi_{2}}{2 g} \mathrm{~d} h_{2}$

For 2-bit A/D converters of Fig. 1, inner integrals are:

$\int_{-g}^{g} \frac{\Psi_{i}}{2 g} \mathrm{~d} h_{i}=s,(s=\mathrm{const} ; i=1,2)$, yielding

$\bar{\Psi}=\int_{-\infty}^{+\infty} s^{2} p(s) \mathrm{d} s=\overline{s^{2}}$, which is the average noise power.

Hence, noise true RMS is:

$$
s_{\mathrm{RMS}}=\sqrt{\bar{\Psi}}=\sqrt{\overline{s^{2}}} .
$$

\subsection{The third central moment of error $e$}

For estimation of the measurement uncertainty, it is first necessary to determine the third central moment of error $[19,20]$ :

$$
M_{3}=\overline{(e-\bar{e})^{3}}
$$

In every sampling instant, the product $\Psi$ consists of the signal square $s^{2}$ and an error $e$ :

$$
\Psi=s^{2}+e
$$

Given that $s^{2}$ and $e$ are stochastically independent [21] variables, and because of $\bar{\Psi}=\overline{s^{2}}+\bar{e}$ and Eq. (3), the average error for an infinitely high number of samples is zero $(\bar{e})$. Therefore $(e-\bar{e})^{3}=e^{3}$ and the third central moment of error $[19,20]$ becomes:

$M_{3}=\overline{e^{3}}=\int_{e_{\min }}^{e_{\max }} e^{3} p(e) \mathrm{d} e$

In every sampling instant, as the result of two-bit sampling, variables $\Psi_{1}$ and $\Psi_{2}$ can deviate from true value of $s$ in the range $[-2 g, 2 g]$. Because $\Psi=\Psi_{1} \cdot \Psi_{2}$, the error $e$ is within range $\left[-4 g^{2}, 4 g^{2}\right]$ and (11) becomes:

$$
M_{3} \leq \int_{-4 g^{2}}^{4 g^{2}}\left|e^{3}\right| p(e) \mathrm{d} e=\int_{-4 g^{2}}^{4 g^{2}}\left(4 g^{2}\right)^{3} p(e) \mathrm{d} e=64 g^{6}
$$

Because the third central moment is finite, the Central limit theorem is valid $[19,20]$ and the variance of the average error is:

$$
\sigma_{\bar{e}}^{2}=\frac{\sigma_{e}^{2}}{N}
$$

where $\sigma_{e}^{2}$ is the variance of a digitized sample's error for an infinite number of samples, and $N$ is the number of samples in the measurement time interval.

\subsection{Theoretical measurement uncertainties of the noise power and the noise true RMS}

Because $s^{2}$ and $e$ are mutually stochastically independent variables in Eq. (10), their variances are related as:

$$
\sigma_{\Psi}^{2}=\sigma_{s^{2}}^{2}+\sigma_{e}^{2}
$$

Let us explore the variance of the product $\Psi$, which is "the mean of square minus square of the mean" [19, 20]:

$\sigma_{\Psi}^{2}=\overline{\Psi^{2}}-\bar{\Psi}^{2}$

The mean of square is determined in probability domain as:

$\overline{\Psi^{2}}=\int_{-2 g}^{2 g} p(s) \mathrm{d} s \int_{-g}^{g} \frac{\Psi_{1}^{2}}{2 g} \mathrm{~d} h_{1} \int_{-g}^{g} \frac{\Psi_{2}^{2}}{2 g} \mathrm{~d} h_{2}$

The variables $\Psi_{1}^{2}$ and $\Psi_{2}^{2}$ can be expressed as $\Psi_{i}^{2}=2 g \cdot\left|\Psi_{i}\right|$ where $i=1,2$. Hence:

$\overline{\Psi^{2}}=\int_{-2 g}^{2 g} p(s) \mathrm{d} s \int_{-g}^{g}(2 g) \frac{\left|\Psi_{1}\right|}{2 g} \mathrm{~d} h_{1} \int_{-g}^{g}(2 g) \frac{\left|\Psi_{2}\right|}{2 g} \mathrm{~d} h_{2}$
$\overline{\Psi^{2}}=(2 g)^{2} \overline{|s|^{2}}=(2 g)^{2} \overline{s^{2}}$

Substituting from Eq. (17) and Eq. (3) into Eq. (15), it is obtained that:

$\sigma_{\Psi}^{2}=\overline{\Psi^{2}}-\bar{\Psi}^{2}=(2 g)^{2} \cdot \overline{s^{2}}-{\overline{s^{2}}}^{2}$

The variance of the noise signal power $s^{2}$ is again "the mean of square minus square of the mean", which is:

$\sigma_{s^{2}}^{2}=\overline{s^{4}}-\bar{s}^{2}$

Combining Eq. (14), Eq. (18) and Eq. (19) the variance of one digitized sample's error is:

$\sigma_{e}^{2}=\sigma_{\Psi}^{2}-\sigma_{s}^{2}=(2 g)^{2} \cdot \overline{s^{2}}-\overline{s^{4}}$

and, due to Eq. (13), the variance of the average error is:

$\sigma_{\bar{e}}^{2}=\frac{(2 g)^{2} \cdot \overline{s^{2}}-\overline{s^{4}}}{N}$ 
Finally, the relative measurement uncertainty for noise power is obtained as:

$\gamma=\frac{\sigma_{\bar{e}}}{\overline{s^{2}}}$

The expression of the relative measurement uncertainty for the noise true RMS value is obtained from Eq. (22) by considering the relation between power $\left(\overline{s^{2}}\right)$ and true RMS ( $\left.s_{\mathrm{RMS}}\right)$ and their uncertainties.

$\overline{s^{2}}=P \cdot(1+\gamma)$

$\sqrt{\overline{s^{2}}}=\sqrt{P} \cdot(1+\varepsilon)$

Squaring both sides of Eq. (24) and developing gives:

$\overline{s^{2}}=P \cdot(1+\varepsilon)^{2}=P \cdot\left(1+2 \varepsilon+\varepsilon^{2}\right)$

Because $\varepsilon$ is much smaller than $1, \varepsilon^{2}$ can be neglected in Eq. (25). Thus, comparing Eq. (23) and Eq. (25), $\varepsilon \approx$ $\gamma / 2$.

Finally, the relative measurement uncertainty for noise true RMS value is obtained as:

$\varepsilon \approx \frac{\sigma_{\bar{e}}}{2 \overline{s^{2}}}$

\subsection{Theoretical measurement uncertainty for Gaussian and uniform noise}

Let us consider that the measured noise is unbiased, $\bar{s}=0$. Then, its variance represents the average power, $\sigma^{2}=\overline{s^{2}}$, for both noise types.

i) For Gaussian unbiased noise, according to $[19,20]$ $\overline{s^{4}}=3 \sigma^{4}$. Then the variance, defined by Eq. (21), becomes:

$$
\sigma_{\bar{e}}^{2}=\frac{\sigma^{2}\left[(2 g)^{2}-3 \sigma^{2}\right]}{N}
$$

Applying approximation by Taylor series $\sqrt{1+x} \approx 1+x / 2$, the standard deviation is:

$\sigma_{\bar{e}}=\frac{\sigma \cdot 2 g}{\sqrt{N}} \sqrt{1-\frac{3 \sigma^{2}}{(2 g)^{2}}} \approx \frac{\sigma \cdot 2 g}{\sqrt{N}}\left[1-\frac{3}{2}\left(\frac{\sigma}{2 g}\right)^{2}\right]$

Thus, according to Eq. (22) and Eq. (28):

$$
\gamma=\frac{2 g}{\sigma \cdot \sqrt{N}}\left[1-\frac{3}{2}\left(\frac{\sigma}{2 g}\right)^{2}\right]
$$

and

$$
\varepsilon \approx \frac{\gamma}{2}=\frac{g}{\sigma \cdot \sqrt{N}}\left[1-\frac{3}{2}\left(\frac{\sigma}{2 g}\right)^{2}\right]
$$

ii) If the noise is uniform, unbiased and uncorrelated with $h_{1}$ and $h_{2}$, then $[19,20]$ :

$\overline{s^{4}}=\frac{9}{5} \sigma^{4}$, for $s \in\{-2 g, 2 g\}$

Using the same procedure,

$$
\begin{aligned}
& \sigma_{\bar{e}}^{2}=\frac{1}{N}\left[(2 g)^{2} \cdot \sigma^{2}-\frac{9}{5} \sigma^{4}\right] \\
& \sigma_{\bar{e}} \approx \frac{\sigma \cdot 2 g}{\sqrt{N}}\left[1-\frac{9}{10}\left(\frac{\sigma}{2 g}\right)^{2}\right] \\
& \gamma=\frac{2 g}{\sigma \cdot \sqrt{N}}\left[1-\frac{9}{10}\left(\frac{\sigma}{2 g}\right)^{2}\right]
\end{aligned}
$$

and

$\varepsilon \approx \frac{\gamma}{2}=\frac{g}{\sigma \cdot \sqrt{N}}\left[1-\frac{9}{10}\left(\frac{\sigma}{2 g}\right)^{2}\right]$

It can be seen that the relative measurement uncertainty depends on noise standard deviation (true RMS) $\sigma$ and instrument parameters $g$ and $N$. This is true for any type of noise - the noise type defines only the second term of the expressions (29), (30), (34) and (35). Therefore, lower measurement uncertainty is achieved by a large number of samples $N$, obtained by a higher sampling frequency and/or by a longer measurement time interval.

\section{Simulation results}

Measurements of noise power and true RMS using the proposed stochastic approach have been faithfully simulated. The duration of measurement interval is $1 \mathrm{~s}$, $\mathrm{A} / \mathrm{D}$ converter input range is $\pm 1 \mathrm{~V}$ and sampling frequencies are set to $0,5 \mathrm{MHz}, 2 \mathrm{MHz}$ or $8 \mathrm{MHz}$. For the first simulation setup, the noise maximal amplitude was perfectly matched with the instrument range: $5 \sigma=2 g=1 \mathrm{~V}$ for the Gaussian and $2 \sqrt{3} \sigma=2 g=1 \mathrm{~V}$ for the uniform noise $[19,20]$. These two points are used to normalize the standard deviation of the input noise, $\sigma$. In subsequent simulation setups, $\sigma$ was reduced by $10 \%$ every time.

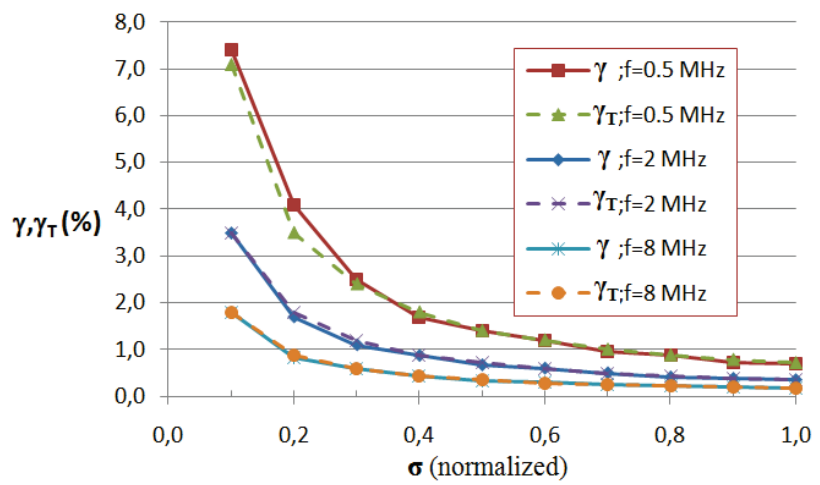

Figure 3 Measurements of the Gaussian noise power - simulated and theoretical relative measurement uncertainty $\left(\gamma\right.$ and $\left.\gamma_{\mathrm{T}}\right)$ vs. the normalized $\sigma$. 
Even when all parameters are unchanged, each simulation run is slightly different, due to the stochastic nature of both the noise $s$ and dithering signals $h_{1}$ and $h_{2}$. Therefore, in order to obtain statistically valid results, 200 simulation runs for each set of parameters are performed and a posteriori statistical analysis of the results is conducted. An average value from a set of 200 simulations is presented by a single point in Figs. 3-6. The relative measurement uncertainty for noise power, $\gamma$, is then compared with the theoretical value, $\gamma_{\mathrm{T}}$, calculated from Eq. (29) and Eq. (34). The changes $\gamma$ and $\gamma_{\mathrm{T}}$, in percentages, versus the normalized $\sigma$ are shown in Figs. 3 and 4 , for Gaussian noise and uniform noise, respectively.

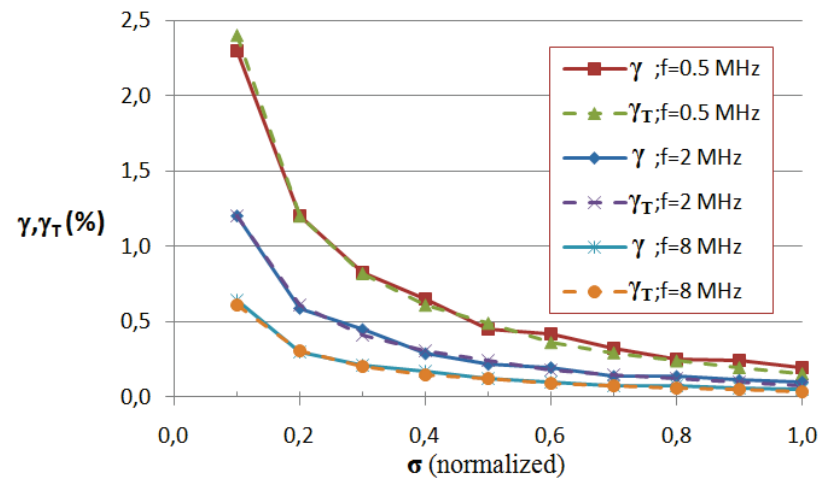

Figure 4 Measurements of the uniform noise power - simulated and theoretical relative measurement uncertainty $\left(\gamma\right.$ and $\left.\gamma_{T}\right)$ vs. the normalized $\sigma$.

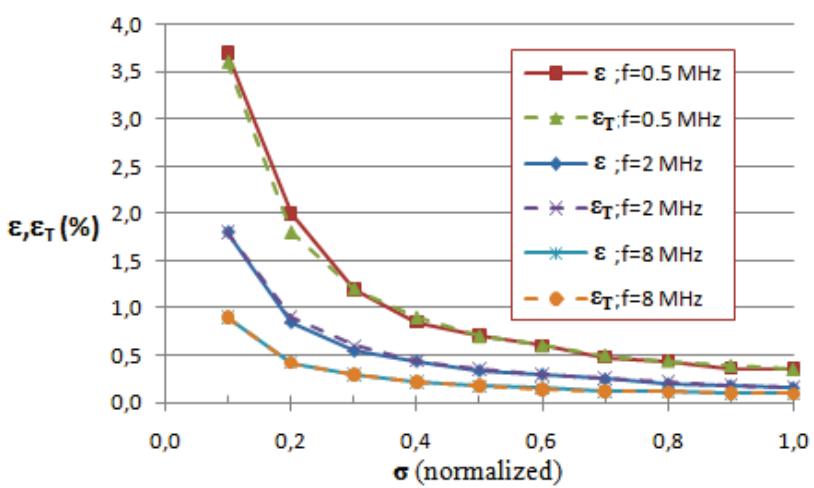

Figure 5 Measurements of the Gaussian noise true RMS - simulated and theoretical relative measurement uncertainty $\left(\varepsilon\right.$ and $\left.\varepsilon_{\mathrm{T}}\right)$ vs. the normalized $\sigma$.

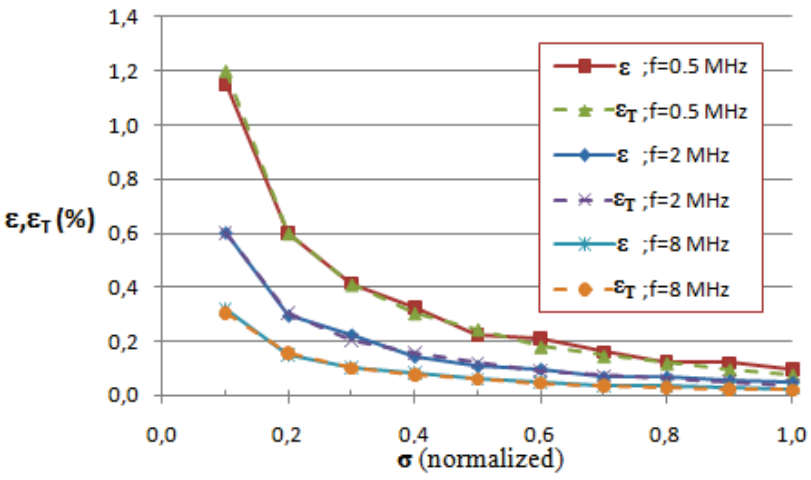

Figure 6 Measurements of the uniform noise true RMS - simulated and theoretical relative measurement uncertainty $\left(\varepsilon\right.$ and $\left.\varepsilon_{\mathrm{T}}\right)$ vs. the normalized $\sigma$.

The changes of relative measurement uncertainty for true RMS, $\varepsilon$ and $\varepsilon_{\mathrm{T}}$, in percentages versus the normalized $\sigma$ are shown in Figs. 5 and 6, for Gaussian noise and uniform noise, respectively. The average value of 200 simulations is compared with the theoretical value of either (30) or (35).

Figs. 3-6 show the expected decrease of uncertainties with the increase of the sampling frequency as well as with the increase of the standard deviation of the noise, $\sigma$. The agreement of simulated and theoretically predicted uncertainties is very good throughout, confirming the validity of the proposed method.

\section{Experimental results}

The proposed method is proven by an experimental platform shown in Fig. 7. Random Number Generator (RNG) is implemented as a stable generator of digitally synthesized random voltage. RNG outputs to a 12-bit D/A converter, which produces a uniform noise signal $s_{\mathrm{p}}$ limited within $\pm 2,5 \mathrm{~V}$. Both RNG and D/A converter operate at $125 \mathrm{kHz}$ rate, which covers most types of lowfrequency noise met in latest graphene-based sensors [1518].

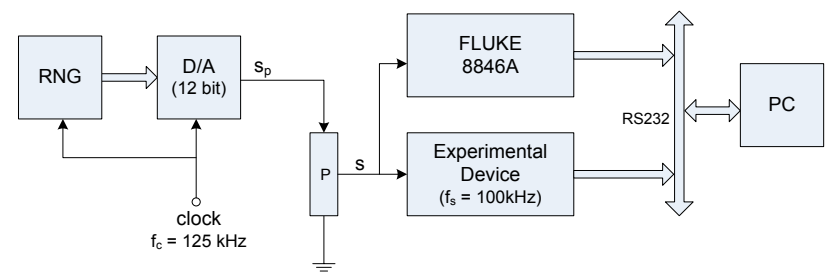

Figure 7 Block diagram of experimental platform

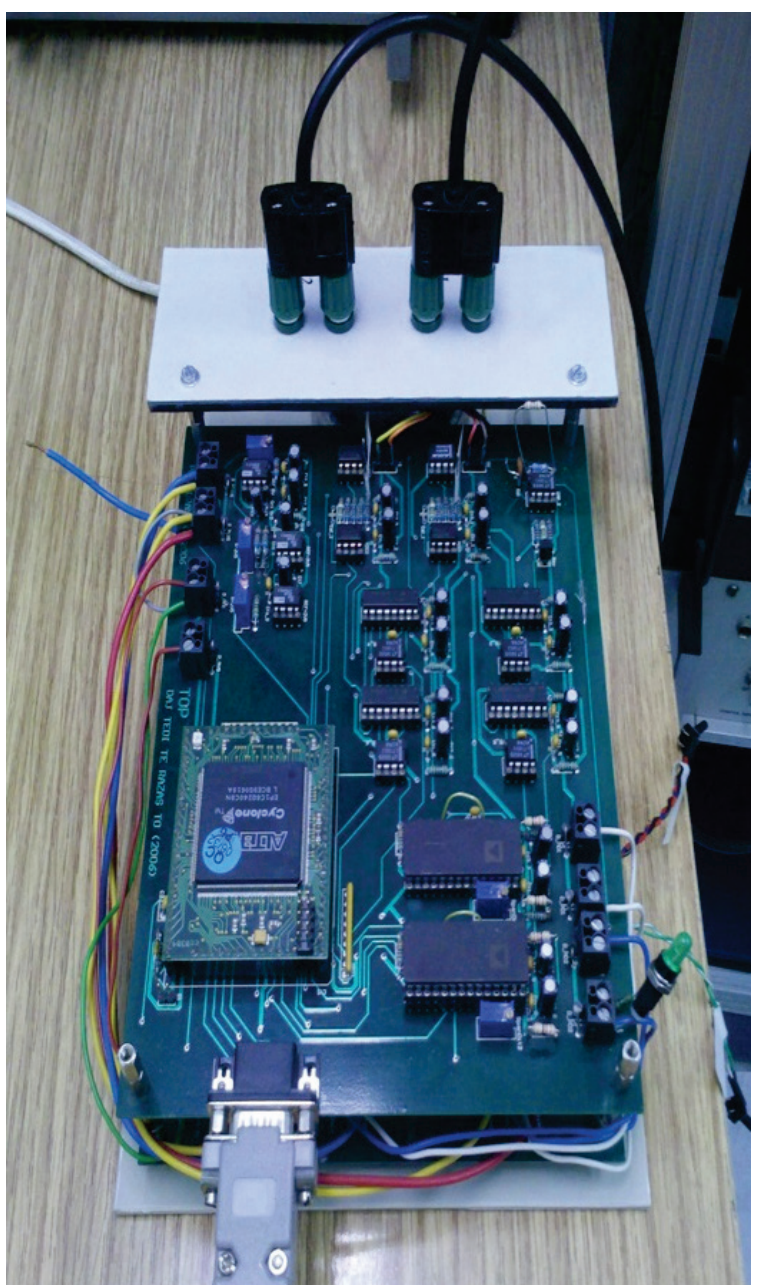

Figure 8 The experimental device 
The generated noise $s_{\mathrm{p}}$ is then adjusted with a voltage divider (potentiometer $\mathrm{P}$ ) to give a noise signal $s$, which is simultaneously measured by the proposed experimental device (shown in Fig. 8) and the standard instrument FLUKE 8846A. The adjustment with potentiometer $\mathrm{P}$ is done for keeping the noise $\mathrm{s}$ within the range of highest possible accuracy of the standard instrument FLUKE 8846A (its declared accuracy is below 0,1\%). The instruments are connected to the supporting PC via RS232.

The experimental device has a low sampling frequency of $100 \mathrm{kHz}$ and the interval of true RMS measurement is 1 second. For each adjusted level of noise $s, 600$ measurements were performed, in order to obtain a valid statistic.

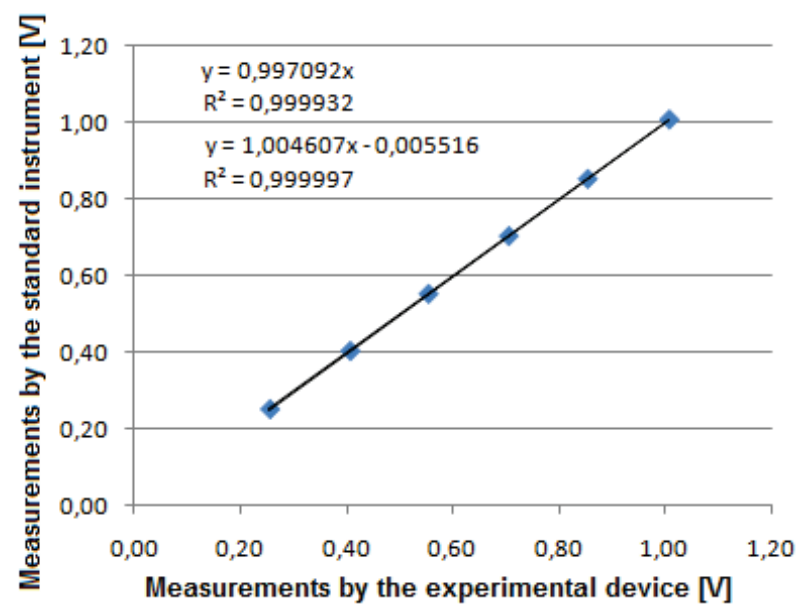

Figure 9 True RMS values measured by the standard instrument FLUKE $8846 \mathrm{~A}$ vs. true RMS values measured by the proposed experimental device.

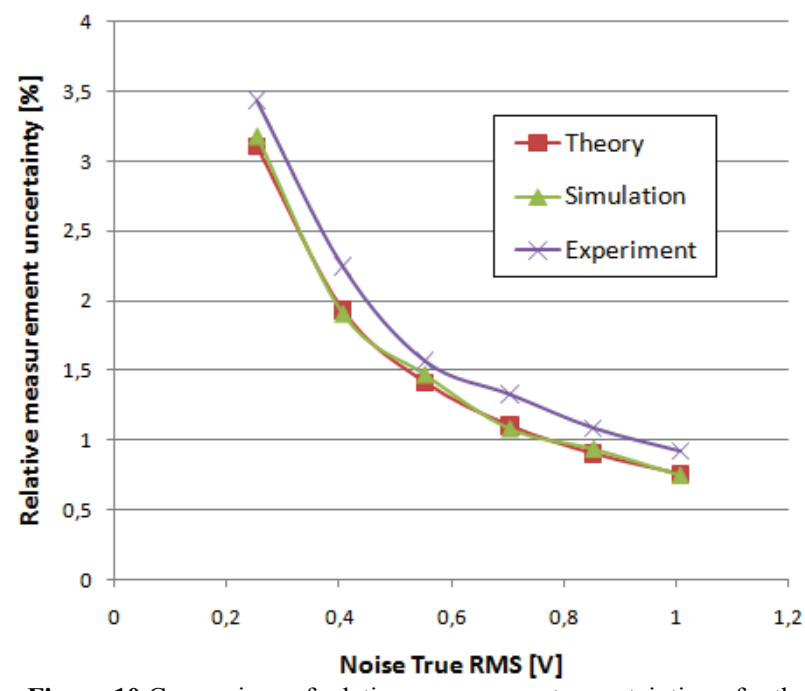

Figure 10 Comparison of relative measurement uncertainties $\varepsilon$ for the proposed experimental device: theoretical calculation, simulation and experiment for the experimental device operating at $100 \mathrm{kHz}$.

Fig. 9 shows the measurement results for 6 noise levels, where each point represents the average of 600 true RMS measurements. Averages measured by the experimental device are on the horizontal $(x)$ axis whereas averages measured by the standard instrument are on the vertical (y) axis. An excellent linear correlation between measurements obtained by the two instruments can be seen. Two proposed interpolation functions are also shown - the first one passes through the origin whereas the second one gives the best Pearson product-moment correlation coefficient $(R)$.

Fig. 10 depicts relative measurement uncertainties of the proposed instrument $(\varepsilon)$, for the same 6 noise levels, enabling a comparison of experimental results with both simulation results and theoretical calculations. Almost a perfect match between simulation results and theoretical calculations, and slightly higher uncertainty values obtained in experiments, can be seen. It is also interesting to investigate the distribution of experimentally obtained measurement errors for the 600 measurements conducted at a certain noise level. Hence, an a posteriori statistical analysis of measurement error was conducted for each noise level and all of them are showing similar trends.

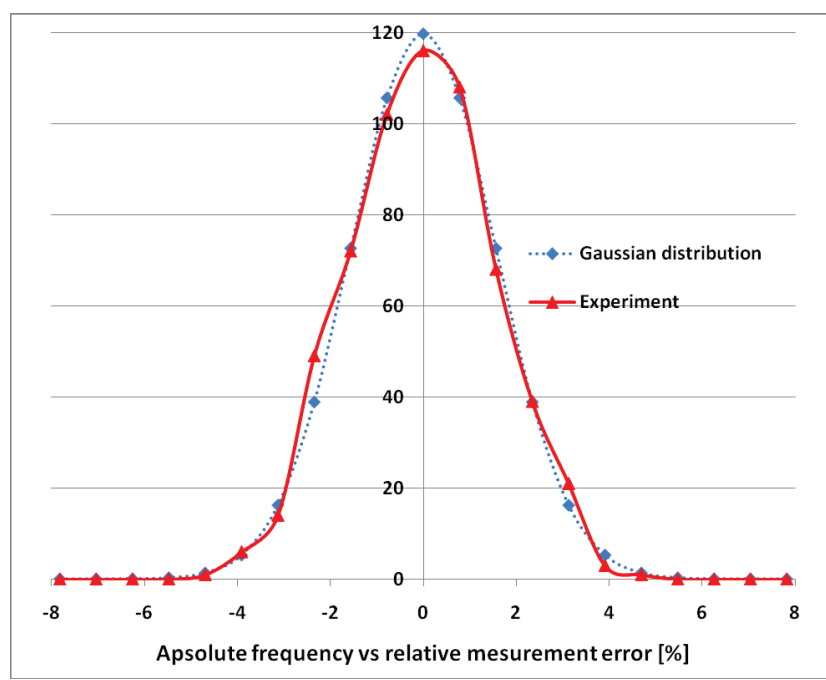

Figure 11 Comparison of experimentally obtained distribution and Gaussian distribution of relative measurement error for the 3rd experimental set of 600 measurements.

As an example, Fig. 11 presents the distribution of experimentally obtained relative measurement error for the $3^{\text {rd }}$ experimental set $\left(s_{\mathrm{RMS}}=0,553 \mathrm{~V}\right)$ and its comparison with the Gaussian distribution. Horizontal axis variable is the relative measurement error, covering the range $\left[-5 \sigma_{\bar{e}}, 5 \sigma_{\bar{e}}\right]$, with an interval width of $0,5 \sigma_{\bar{e}}$, in this case $0,782 \%$. It can be seen that, even at this very low $100 \mathrm{kHz}$ sampling frequency, experimentally obtained errors are distributed very close to Gaussian distribution, with all values within $\pm 3 \sigma_{\bar{e}}$. Almost the fifth of the 600 measurements give the relative error below $0,391 \%\left(0,25 \sigma_{e}^{-}\right)$and more than $50 \%$ of the experiments give the relative error below $1,173 \%$, i.e. within $\left[-0,75 \sigma_{\bar{e}}, 0,75 \sigma_{\bar{e}}\right]$.

\section{Discussion}

If state of the art electronic components were used, sampling rate of $500 \mathrm{MHz}$ could be achieved. This would increase the number of samples $\mathrm{N}$ by a factor of $500 / 8=62,5$ with the respect to the $8 \mathrm{MHz}$ simulations and $500 / 0,1=5000$ versus the $100 \mathrm{kHz}$ experiments. Consequently, according to equations (29), (30), (34) and (35), the relative measurement uncertainty would be 
reduced $\sqrt{N}=7,9$ times (vs. simulations) or $\sqrt{N}=70,7$ times (vs. experiments), enabling very accurate measurement of noise power and true RMS. It would give measurement uncertainty below $200 \mathrm{ppm}$, providing that the noise level and instrument input range are suitably matched.

Also, for substance identification by graphene sensor, noise spectral power density over very low frequencies (starting from $0,001 \mathrm{~Hz}$ ) is very important. Regardless of applied method, the required frequencies define the minimal measurement interval of $1000 \mathrm{~s}$. In such a measurement interval, the experimental device would measure $\sqrt{1000}=31,6$ times more precise than in the presented experiment. This confirms that the developed experimental measurement device can be utilized in further research in the area of graphene sensor applications.

The experiment is a measurement of low-frequency uniform noise, generated in controlled conditions at $125 \mathrm{kHz}$ rate. This resembles the noise encountered in application of the emerging graphene-based sensors [1518], where the noise is the signal that needs to be measured. Hence, this experiment has a practical significance as it proves a possibility of utilizing the stochastic measurement approach in conjunction with graphene-based sensors. Very simple instrument hardware yields lower power consumption than classical digital instruments, thus providing good autonomy of batterysupplied graphene sensor systems [18].

\section{Conclusion}

The paper presents a new application of stochastic digital measurement approach, for measurement of noise power and true RMS. The instrument is very simple, which, together with the utilization of the very fast 2-bit flash A/D converters, allows a very high sampling frequency. New expressions for relative measurement uncertainty are derived by applying the statistical theory of samples and the Central limit theorem. The theoretical analyses in this paper for the first time include the influence of the input signal's stochastic nature.

Simulation results for Gaussian and uniform noise show a very good match with the values calculated from theoretical formulae, confirming a predictable measurement uncertainty, which can be further reduced by increasing the sampling rate and/or prolonging the measurement time interval. The prototype instrument gives results for uniform noise very close to the standard instrument FLUKE 8846A, even at relatively short time interval of $1 \mathrm{~s}$.

In summary, the theoretical, simulation and experimental challenges are answered in both engineering and metrological sense. The results are especially significant for applications which require very simple hardware and low power supply, like long-lasting and complex measurements required by graphene sensors.

\section{Acknowledgements}

This work was supported in part by the Ministry of Science and Technological Development of the Republic of Serbia under research grant No. TR32019, and by the Provincial Secretariat for Science and Technological Development of Autonomous Province of Vojvodina (Republic of Serbia) under research grant No. 114-4512723.

\section{References}

[1] D' Antona, G.; Ferrero, A. Digital Signal Processing for Measurement Systems: Theory \& Applications, SpringerVerlag, 2006.

[2] Rathore, T. S. Digital Measurement Techniques, CRC Press, 2003.

[3] Kay, S.M. Fundamentals of Statistical Signal Processing, Volume I: Estimation Theory, New Jersey: Prentice Hall PTR, 1993.

[4] Vujičić, V.; Župunski, I.; Mitrović, Z.; Sokola, M. Measurement in a Point versus Measurement Over an Interval. // Fundamental and Applied Metrology, Proceedings of XIX IMEKO World Congress / Lisbon, 2009, pp. 1128-1132.

[5] Vujičić, V.; Milovančev, S.; Pešaljević, M.; Pejić, D.; Župunski, I. Low Frequency Stochastic True RMS Instrument. // IEEE Transactions on Instrumentation and Measurement. 48, 2(1999), pp. 467-470. https://doi.org/10.1109/19.769630

[6] Pejić, D.; Vujičić, V. Accuracy Limit of High-Precision Stochastic Watt-hour Meter. // IEEE Transactions on Instrumentation and Measurement. 49, 3(2000), pp. 617620. https://doi.org/10.1109/19.850404

[7] Vujičić, V. Generalized Low Frequency Stochastic True RMS Instrument. // IEEE Transactions on Instrumentation and Measurement. 50, 5(2001), pp. 1089-1092. https://doi.org/10.1109/19.963164

[8] Santrač, B.; Sokola, M.; Mitrović, Z.; Župunski I.; Vujičić, V. A Novel Method for Stochastic Measurement of Harmonics at Low Signal-to-Noise Ratio. // IEEE Transactions on Instrumentation and Measurement. 58, 10(2009), pp. 3434-3441. https://doi.org/10.1109/TIM.2009.2017661

[9] Sovilj, P.; Milovančev S.; Vujičić, V. Digital Stochastic Measurement of a Nonstationary Signal with an Example of EEG Signal Measurement. // IEEE Transactions on Instrumentation and Measurement. 60, 9(2011), pp. 32303232. https://doi.org/10.1109/TIM.2011.2128670

[10] Vasilescu, G. Electronic Noise and Interfering Signals: Principles and Applications, Springer, 2004.

[11] Ott, H. W. Noise Reduction Techniques in Electronic Systems, John Wiley \& Sons, 1988.

[12] Kennedy, G.; Davis, B.; Prasanna, S. R. M. Electronic Communication Systems, $5^{\text {th }}$ ed, McGraw-Hill, 2011.

[13] Fish, P. J. Electronic Noise and Low Noise Design, Macmillan Press, 1993. https://doi.org/10.1007/978-1-349-23060-0

[14] Peterson, A. P. G. Handbook of Noise Measurement, General Radio Company $9^{\text {th }}$ ed, 1980.

[15] Djurić, Z. G.; Jokić, I. M.; Peleš A. Highly Sensitive Graphene-based Chemical and Biological Sensors with Selectivity Achievable Through Low-frequency Noise Measurement - Theoretical Considerations, Proceedings of the conference MIEL 2014 / Belgrade, 2014, pp. 153-156. https://doi.org/10.1109/MIEL.2014.6842108

[16] Djurić, Z.; Jokić, I.; Peleš, A. Fluctuations of the Number of Adsorbed Molecules due to Adsorption-desorption Processes Coupled with Mass Transfer and Surface Diffusion in Biochemical MEMS Sensors. // Microelectronic Engineering, Elsevier, 124, (2014) pp. 8185. https://doi.org/10.1016/j.mee.2014.06.001 
[17] Djurić, Z.; Jokić, I.; Radulović, K. Resonant Frequency and Phase Noise of Nanoelectromechanical Oscillators Based on Two-dimensional Crystal Resonators. // Procedia Engineering, 87, 2014, pp. 460-463.

https://doi.org/10.1016/j.proeng.2014.11.382

[18] Vujičić, V.; Radonjić, A.; Vujičić, B.; Beljić, Ž. Stochastic Measurement of the Spectral Power Density of Lowfrequency Noise Generated by Graphene-based Chemical and Biological Sensors - Case Study, Proceedings of the conference IcETRAN 2014/ Srebrno Jezero, 2014, pp. MLI1.4-1-3.

[19] Papoulis, A. Probability, Random Variables and Stochastic Processes $3^{\text {rd }}$ edition, Mcgraw-Hill College, 1991.

[20] Rice, J. Mathematical Statistics and Data Analysis 2nd edition, Duxbury Press, 1995.

[21] Wagdy, M. F.; Ng, W. Validity of uniform quantization error model for sinusoidal signals without and with dither. // IEEE Transactions on Instrumentation and Measurement. 38, 3(1989), pp. 718-722. https://doi.org/10.1109/19.32180

\section{Authors' addresses}

Platon Sovilj, Ph.D. Associate Professor

University of Novi Sad, Faculty of Technical Sciences, Trg Dositeja Obradovica 6, 21000 Novi Sad, Serbia

E-mail: platon@uns.ac.rs

\section{Bojan Vujičić, M.Sc.}

University of Novi Sad, Faculty of Technical Sciences, Trg Dositeja Obradovica 6, 21000 Novi Sad, Serbia

E-mail: bojanvuj@uns.ac.rs

Matija Sokola, Ph.D. Professor of vocational studies School of Professional Higher Education,

Školska 1, 21101 Novi Sad, Serbia

E-mail: sokola@vtsns.edu.rs

\section{Dragan Pejić, Ph.D. Assistant Professor}

University of Novi Sad, Faculty of Technical Sciences, Trg Dositeja Obradovica 6, 21000 Novi Sad, Serbia

E-mail: pejicdra@uns.ac.rs

\section{Željko Beljić, M.Sc. Researcher}

University of Novi Sad, Faculty of Technical Sciences, Trg Dositeja Obradovica 6, 21000 Novi Sad, Serbia

E-mail: zbeljic@uns.ac.rs

\section{Zoran Mitrović, Ph.D. Full Professor}

University of Novi Sad, Faculty of Technical Sciences, Trg Dositeja Obradovica 6, 21000 Novi Sad, Serbia

E-mail: zoranmit@uns.ac.rs 